\title{
Antibacterial and Antioxidant Compounds from the Flower Extracts of Vernonia amygdalina
}

\author{
Abere Habtamu and Yadessa Melaku (D) \\ Chemistry Department, Applied Natural Sciences, Adama Science and Technology University, Adama, Ethiopia \\ Correspondence should be addressed to Yadessa Melaku; yadessamelaku2010@gmail.com
}

Received 30 November 2017; Accepted 4 February 2018; Published 20 March 2018

Academic Editor: Masahiro Oike

Copyright ( $\odot 2018$ Abere Habtamu and Yadessa Melaku. This is an open access article distributed under the Creative Commons Attribution License, which permits unrestricted use, distribution, and reproduction in any medium, provided the original work is properly cited.

\begin{abstract}
Vernonia amygdalina is traditionally used in Ethiopia to treat various diseases. This prompted us to isolate bioactive compounds from the flowers of this plant. The $\mathrm{CHCl}_{3}$ extract after silica gel column chromatography has led to the isolation of two compounds identified as tricosane (1) and vernolide (2), while the acetone extract furnished isorhamnetin (3) and luteolin (4). The acetone extract and isorhamnetin significantly scavenged the 2,2-diphenyl-1-picrylhydrazyl (DPPH) radical by 91.6 and $94 \%$, respectively. It was also shown that the acetone extract and isorhamnetin inhibited lipid peroxidation by 74 and $80 \%$, respectively. The extracts and isolated compounds were also evaluated for their antibacterial activity with the $\mathrm{CHCl}_{3}$ extract and vernolide showing strong activity against $S$. aureus with an inhibition zone of 21 and $19 \mathrm{~mm}$, respectively. On the other hand, the acetone extract and isorhamnetin were active against all bacterial pathogens tested. The work presented herein has demonstrated that vernolide and isorhamnetin had antibacterial activity. The antioxidant activity displayed by the flowers of $V$. amygdalina is accounted to the presence of isorhamnetin. Therefore, the biological activities displayed by the extracts and isolated compounds from this plant corroborate the traditional uses of this plant by the local people against various diseases.
\end{abstract}

\section{Introduction}

Vernonia amygdalina Del. is a soft woody shrub or tree belonging to the family Asteraceae and genus Vernonia [1]. The plant is predominantly found in Africa. It is a perennial plant characterized by its bitter sap from the leaf which has been widely explored for its medicinal use. This plant grows to $10 \mathrm{~m}$ tall with petiole leaf of about $6 \mathrm{~mm}$ in diameter and elliptic in shape [2]. In the Ethiopian highland, V. amygdalina has been classified by the farmer as a multipurpose fodder tree with high biomass yield, easy propagation, high adaptability, and high compatibility with other crops which do not compete with them for soil nutrients or moisture but instead help to improve the soil fertility and growth of perennial crops [3]. V. amygdalina, locally called ebicha in Afan Oromo and Grawa in Amharic (Ethiopia), is quite commonly used in Ethiopia in the preparation of local beer and also as fumigant. It is also used as fire wood [4].

$V$. amygdalina is traditionally used to treat many ailments including diabetes $[5,6]$, antihelminth, antimalarial, laxative, digestive tonic, appetizer, and febrifuge [7]. In some African countries including Ethiopia, $V$. amygdalina is among medicinally significant plants used against malaria, helminth infections, gastrointestinal disorders, and fever [8]. The species is also used to promote wound healing [9] and to treat microbial infections [10]. The main bioactive constituents of the leaves were reported as sesquiterpene lactones [11]. Some of them include vernonioside $A 1$, vernonioside $\mathrm{A} 2$, vernonioside $\mathrm{B} 1$, vernonioside $\mathrm{B} 2[12,13]$, vernodalin, vernolepin, vernomygdin, vernodalol, and vernodalinol $[14,15]$. Despite numerous report on the secondary metabolite profile of the leaves, to the best of our knowledge there is no prior scientific report on the chemical constituents of the flowers of this species. Furthermore, the antioxidant and antibacterial activities of the flower extracts and constituents of $V$. amygdalina have not been studied. Hence, in this paper, we report the results of our investigation of effects of the extracts and constituents of the flowers of $V$. amygdalina on E. coli, K. pneumonia, P. mirabilis, S. aureus, and S. bacillus. The results of the evaluation of the radical 


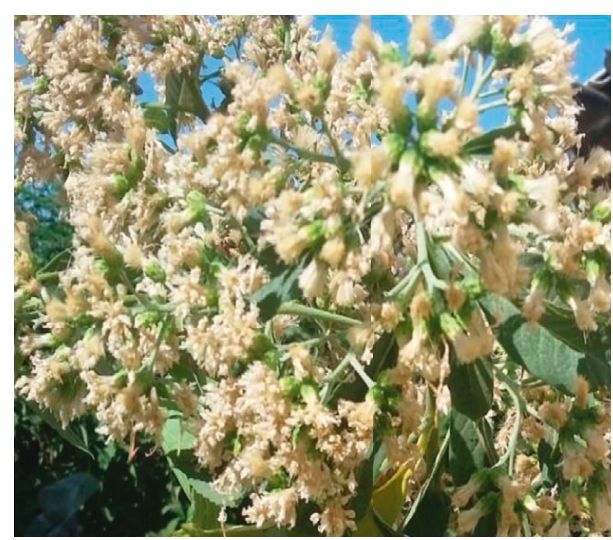

(a)

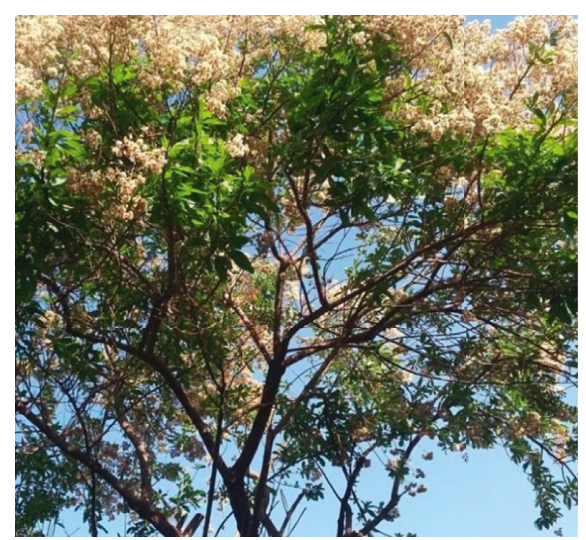

(b)

Figure 1: Flowers (a) and aerial part (b) of Vernonia amygdalina from Wonji, Ethiopia, on February 12, 2017 (picture taken by Abere Habtamu).

scavenging activities and antilipid peroxidation potentials of the flower extracts and constituents of $V$. amygdalina are also described herein.

\section{Materials and Methods}

2.1. Plant Material. The flowers of $V$. amygdalina were collected on February 12, 2017 from Wonji district, which is located at $107 \mathrm{~km}$ Southeast of Addis Ababa, Ethiopia. Identification and authentication of the plant specimen was done at the National Herbarium of Addis Ababa University by Mr. Melaku Wondafrash and voucher specimen (AB002) was deposited (Figure 1).

2.2. Extraction and Isolation. The air-dried powdered flowers of $V$. amygdalina (500 g) were successively extracted with hexane $(2 \mathrm{~L})$, chloroform $(2 \mathrm{~L})$, and acetone $(2 \mathrm{~L})$ each for 24 hours at room temperature with frequent agitation on the automatic agitator. It was filtered and concentrated to furnish $2.2 \mathrm{~g}(0.4 \%), 8.9 \mathrm{~g}(1.78 \%)$, and $9.4 \mathrm{~g}(1.91 \%)$, respectively.

The chloroform extract $(4.5 \mathrm{~g}$ ) was adsorbed in an equal amount of silica gel and fractionated over silica gel (160 g) column chromatography. The column was eluted with hexane: ethyl acetate: methanol of increasing polarities to furnish 14 fractions. A volume of $100 \mathrm{~mL}$ each was collected. The first fraction was collected with $100 \%$ hexane. F2 to F10 were eluted with hexane : EtOAc with the ratio 9:1, $4: 1,7: 3$, $7: 3,3: 2,3: 7,1: 4,1: 4$, and $1: 9$, respectively. The next two, F11 and F12, were collected using 100\% EtOAc. The column was ended after collecting F13 and F14 using EtOAc: $\mathrm{MeOH}$ with ratio $9: 1$ and $6: 4$, respectively. F1 (22 mg) and F10 (77 mg) were shown to have a single spot on TLC and hence were analyzed with NMR, UV, and IR.

Likewise, the acetone extract $(5 \mathrm{~g})$ was adsorbed and fractionated over silica gel (180 g) column chromatography to furnish 15 fractions. In each case, a volume of $100 \mathrm{~mL}$ was collected. The first four fractions were collected using $\mathrm{CHCl}_{3}$. F5-F10 were collected using $\mathrm{CHCl}_{3}: \mathrm{MeOH}$ with the ratio $95: 5,9: 1,9: 1,9: 1,85: 15$, and $4: 1$, respectively. The last five fractions were collected using $\mathrm{CHCl}_{3}: \mathrm{MeOH}(2: 3)$. F9 (70 mg) was shown to have one spot on TLC and hence was analyzed with NMR, UV and IR.

2.3. Antibacterial Activities. The antibacterial activities of the extracts and constituents of the flower of $V$. amygdalina were checked using agar well diffusion method [16] against five bacterial strains, three Gram negative (Escherichia coli, Klebsiella pneumoniae, and Proteus mirabilis) and two Gram positive (Staphylococcus aureus and bacillus). Bacterial cultures were maintained on nutrient Muller-Hinton agar at $37^{\circ} \mathrm{C}$, and the cultures were kept in appropriate media slants and stored at $4^{\circ} \mathrm{C}$ until used. Colonies of bacteria (24-hour old culture) were diluted by physiological normal saline $(0.85 \%)$, to make a $0.1 \mathrm{McFarland}$ standard suspension, and then the bacteria was inoculated into sterile Petri dishes of $60 \mathrm{~mL}$ of Muller-Hinton agar plates. The plates were shaken gently to allow evenly mixing of bacterial cells and agar. All samples were dissolved in methanol to furnish $10 \mathrm{mg} / \mathrm{mL}$. From each sample, $100 \mu \mathrm{L}$ of each concentration saturated with discs $(6.00 \mathrm{~mm}$ diameter disc) was placed on plate and incubated at $37^{\circ} \mathrm{C}$ for 24 hours. The diameters of the inhibition zones were calculated. Clear inhibition zones formed around the discs indicated the presence of antibacterial activity [16]. Control wells containing neat solvents (negative control) and chloramphenicol (positive control) were also run parallel in the same plate.

2.4. Antioxidant Assay. The antioxidant activities of the extracts and constituents were studied using DPPH and ferric thiocyanate methods.

2.4.1. DPPH Radical Scavenging Assay. The radical scavenging assay of the extract and constituents of the flowers of $V$. amygdalina was assessed using $\mathrm{DPPH}$ according to the following procedure [17]: the $\mathrm{CHCl}_{3}$ extract was dissolved in methanol to afford $1 \mathrm{mg} / \mathrm{mL}$. It was serially diluted in methanol to give concentration of 500, 250, 125, and $62.5 \mu \mathrm{g} / \mathrm{mL}$. To $1 \mathrm{~mL}$ of each concentration, $4 \mathrm{~mL} \mathrm{DPPH}$ 


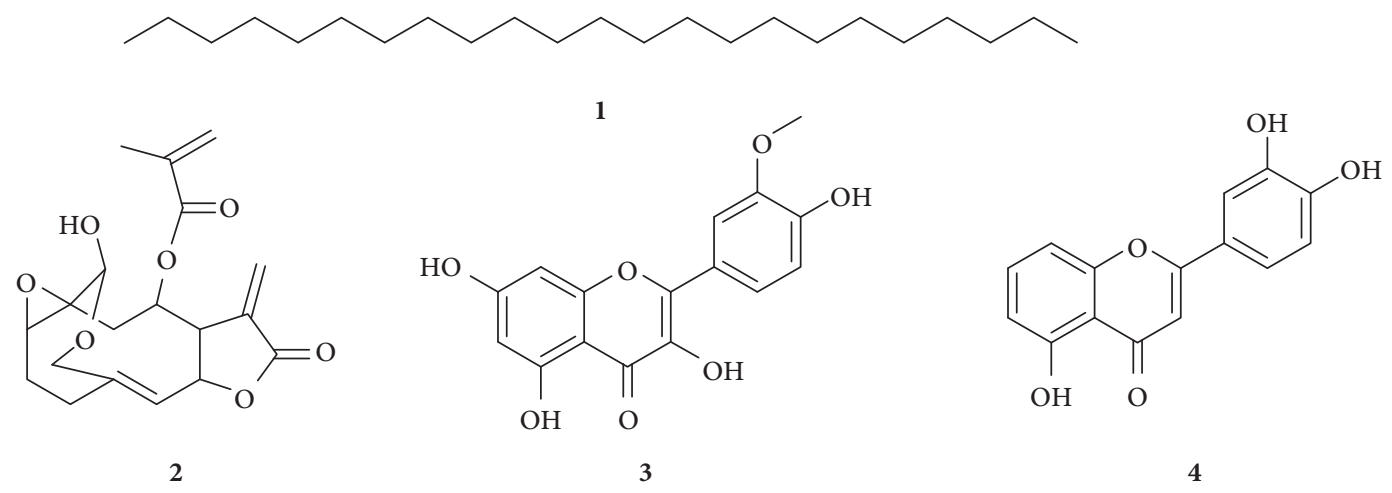

Figure 2: Compounds isolated from the flower extracts of V. amygdalina.

(0.04\% DPPH in $\mathrm{MeOH}$ ) was added to make 100, 50, 25, and $12.5 \mu \mathrm{g} / \mathrm{mL}$ solutions. This was repeated for the acetone extract and pure constituents. Then, all the samples prepared were incubated in an oven at $37^{\circ} \mathrm{C}$ for $30 \mathrm{~min}$ and then absorbance was recorded at $517 \mathrm{~nm}$ using a UV-Vis spectrophotometer. The experiments were performed in triplicates. The percentage inhibition was calculated using the following formula:

$$
\% \text { inhibition }=\frac{\left(A_{\text {control }}-A_{\text {extract }}\right)}{A_{\text {control }}} \times 100,
$$

where $A_{\text {control }}$ is the absorbance of DPPH solution and $A_{\text {extract }}$ is the absorbance of the test sample (DPPH solution plus sample).

2.4.2. Ferric Thiocyanate Method. The antioxidant potential of the extracts and constituents of the flowers of $V$. amygdalina was also assessed according to the method of Nagatsu [18]. Each $0.1 \mathrm{mg}$ of the extracts and pure compounds of $V$. amygdalina, $100 \mu \mathrm{L}$ of linoleic acid, $\mathrm{EtOH}(5 \mathrm{~mL})$, and phosphate buffer $(5 \mathrm{~mL}, 0.05 \mathrm{M}, \mathrm{pH}=7)$ in water were separately added into a vial and incubated at $40^{\circ} \mathrm{C}$ in an oven. After $24 \mathrm{~h}, 0.1 \mathrm{~mL}$ from each were taken and added into a vial containing $75 \%$ aqueous $\mathrm{EtOH}(7 \mathrm{~mL}), 30 \%$ of $\mathrm{NH}_{4} \mathrm{SCN}$ $(0.15 \mathrm{~mL})$, and $0.15 \mathrm{~mL}$ of $0.02 \mathrm{M} \mathrm{FeCl}_{2}$ in $3.5 \% \mathrm{HCl}$. Each was then subjected to UV-Vis spectrophotometery to record the absorbance at $500 \mathrm{~nm}$. Absorbance of the blank and ascorbic acid were done in the same fashion. The experiments were performed in triplicates. The percentage inhibition using ferric thiocyanate method is calculated according to the following formula:

$$
\text { Percentage inhibition }=100-\left(\frac{\mathrm{As}}{\mathrm{Ab}} \times 100\right) \% \text {, }
$$

where As is the absorbance of the sample and $\mathrm{Ab}$ is the absorbance of the blank [19].

\section{Results and Discussion}

Four compounds were isolated and characterized from the flower extracts of $V$. amygdalina (Figure 2).

Compound 1 (22 mg) was obtained as a white power from the $\mathrm{CHCl}_{3}$ extract of the flower of $V$. amygdalina. The
${ }^{1} \mathrm{H}-\mathrm{NMR}$ spectrum of $\mathbf{1}$ exhibited signal at $\delta 0.9(6 \mathrm{H}, t)$ accounted to the presence of terminal methyl group. A broad singlet observed at $\delta 1.28(42 \mathrm{H}, b r . s)$ is a characteristic of many overlapping protons on methylene carbons. The proton decoupled ${ }^{13} \mathrm{C}-\mathrm{NMR}$ spectrum of $\mathbf{1}$ with the aid of DEPT-135 suggested the presence of twenty-three carbons of which the signal observed at $\delta 14.1$ is evident for the presence of terminal methyl group. The remaining carbons are all methylenes. The NMR spectral data generated for compound 1 agreed well with tricosane (Figure 2). This compound has not yet been reported from the genus.

Compound $2(77 \mathrm{mg})$ was obtained as yellow solid from the chloroform extract of the flower of $V$. amygdalina. It was eluted with hexane:ethyl acetate (1:9). The ${ }^{1} \mathrm{H}-\mathrm{NMR}$ spectral data of compound 2 (Supplementary Material 1) showed the presence of exomethylene $\delta$-lactone at $\delta 6.3(1 \mathrm{H}$, $d)$ and $\delta 5.9(1 \mathrm{H}, d)$. Other diastereotopic methylene protons were evident at $\delta 6.1(1 \mathrm{H}, d)$ and $5.7(1 \mathrm{H}, d)$. Another olefinic methine proton is observed at $\delta 5.5(1 \mathrm{H}, d)$. The signal at $\delta$ $5.2(1 \mathrm{H}, t)$ is due to methine proton on oxygenated carbon. Methylene protons on oxygenated carbons are evident at $\delta$ 4.6 and $3.7(2 \mathrm{H}, d, \mathrm{H}-15)$. The signal at $\delta 4.5(1 \mathrm{H})$ indicated that the presence of methine proton on carbon bearing two oxygens. Moreover, the spectral data of this compound showed one methyl group on quaternary carbon at $\delta 1.9(3 \mathrm{H}$, $s)$. The ${ }^{13} \mathrm{C}-\mathrm{NMR}$ spectral data (Supplementary Material 2) displayed the presence of nineteen carbon resonances which agreed well with literature reported from vernolide [20] whose structure is shown in Figure 2. The structure was further confirmed with extensive 2D-NMR including COSY, HSQC, and HMBC (Supplementary Materials 4-6).

Compound 3 (70 $\mathrm{mg}$ ) was isolated from the acetone extract of the flower of $V$. amygdalina. It was eluted using $\mathrm{CHCl}_{3}: \mathrm{MeOH}(85: 15)$ as an eluent and visualized as a yellow spot after spraying with vanillin in $\mathrm{H}_{2} \mathrm{SO}_{4}$. Analysis of the proton NMR spectrum of compound 3 (Supplementary Material 7) showed signal at $\delta 12.7(1 \mathrm{H}, s)$ due to the chelated hydroxy group which is evident for the presence of $5-\mathrm{OH}$. The three aromatic proton signals at $\delta 7.5(1 \mathrm{H}, d$, $\left.J=2.00 \mathrm{~Hz}, \mathrm{H}-2^{\prime}\right), 7.6\left(1 \mathrm{H}, d d, J=8.4 \mathrm{~Hz}\right.$ and $\left.2.00 \mathrm{~Hz}, \mathrm{H}-6^{\prime}\right)$, and $6.9\left(1 \mathrm{H}, d, J=8.4 \mathrm{~Hz}, \mathrm{H}-5^{\prime}\right)$ are typical of flavonoid with $3^{\prime}, 4^{\prime}$-disubstituted B-ring. The other aromatic proton signals at $\delta 6.4(1 \mathrm{H}, d, J=2 \mathrm{~Hz}, \mathrm{H}-8)$ and $6.2(1 \mathrm{H}, d, J=2 \mathrm{~Hz}, \mathrm{H}-6)$ are apparently due to meta coupled protons on the A-ring of 
TABLE 1: Inhibition zone of the extracts and pure compounds of flowers of $V$. amygdalina.

\begin{tabular}{|c|c|c|c|c|c|}
\hline \multirow{2}{*}{ Extract/compounds/control } & \multicolumn{5}{|c|}{ Zone of inhibition $(\mathrm{mm})$} \\
\hline & E. coli & K. pneumoniae & P. mirabilis & S. aureus & S. bacillus \\
\hline Chloroform extract & 6 & 6 & 6 & 21 & 6 \\
\hline Acetone extract & 10 & 12 & 11 & 17 & 12 \\
\hline Vernolide & 10 & 12 & 6 & 19 & 12 \\
\hline Isorhamnetin & 10 & 14 & 12 & 11 & 9 \\
\hline Chloramphenicol & 18 & 18 & 18 & 18 & 18 \\
\hline DMSO (control) & 0 & 0 & 0 & 0 & 0 \\
\hline
\end{tabular}

Chloramphenicol and DMSO were used as the positive and negative controls, respectively.

flavonoid. The presence of one methoxy group is evident at $\delta 3.8(3 \mathrm{H}, \mathrm{s})$. The presence of $\alpha, \beta$-unsaturated ketone is evident from the appearance of the carbonyl carbon signal at $\delta$ 178.3. Other signals in the ${ }^{13} \mathrm{C}-\mathrm{NMR}$ spectrum (Supplementary Material 8) were observed at $\delta 164.5$ (C-7), 161.7 (C-9), 156.7 (C-5), $156.0(\mathrm{C}-2), 149.1\left(\mathrm{C}-4^{\prime}\right), 145.6\left(\mathrm{C}-3^{\prime}\right)$, 138.0 (C-3), $121.2\left(\mathrm{C}-1^{\prime}\right), 121.0\left(\mathrm{C}-6^{\prime}\right), 116.1\left(\mathrm{C}-5^{\prime}\right), 115.8$ $\left(\mathrm{C}-2^{\prime}\right), 104.6$ (C-10), 98.9 (C-6), and 94.0 (C-8). The carbon resonance at $\delta 60.0$ is due to the presence of the methoxy group. Based on the above spectral data, compound 3 was identified as isorhamnetin whose structure is shown in Figure 2.

Compound 4 was isolated from the acetone extract of the flower of $V$. amygdalina. It was eluted using $\mathrm{CHCl}_{3}: \mathrm{MeOH}$ $(4: 1)$ as an eluent and visualized as a yellow spot after spraying with vanillin in $\mathrm{H}_{2} \mathrm{SO}_{4}$. The ${ }^{13} \mathrm{C}-\mathrm{NMR}$ spectrum of 4 with the aid of DEPT-135 revealed the presence of fifteen carbon resonances which agreed well with the literature reported for luteolin (Figure 2).

3.1. Antibacterial Activity. The antibacterial activities of the hexane, chloroform, acetone extract, and pure constituents of the flowers of $V$. amygdalina were investigated using agar well diffusion method, against the selected human pathogens such as E. coli, K. pneumoniae, P. mirabilis, S. aureus, and $S$. bacillus. The results are presented in Table 1.

The extracts and isolated compounds showed considerable difference in antibacterial activities against all selected bacteria's with zone of inhibition ranging from 6 to $21 \mathrm{~mm}$ (Table 1). The acetone and chloroform extracts of the flowers of $V$. amygdalina demonstrated pronounceable activity against $S$. aureus (Figure 3) compared to chloramphenicol used as a standard antibiotic. This is in conformity with the result reported for the leaf extract of $V$. amygdalina against $S$. aureus [21]. The activity displayed by the chloroform extract is likely accounted to the presence of vernolide which showed an inhibition zone of about $19 \mathrm{~mm}$. This is significantly higher than the activity displayed by chloramphenicol. Vernolide exhibited relatively better activity against Gram-positive bacteria with maximum inhibition zone $(19 \mathrm{~mm})$ observed for $S$. aureus. This is in close agreement with the literature reported for same compound [20]. The zone of inhibition displayed by the constituents of the flowers of $V$. amygdalina is depicted in Figure 3. The chloroform extract was found insensitive against E. coli, K. pneumonia, P. mirabilis, and S. bacillus. On the

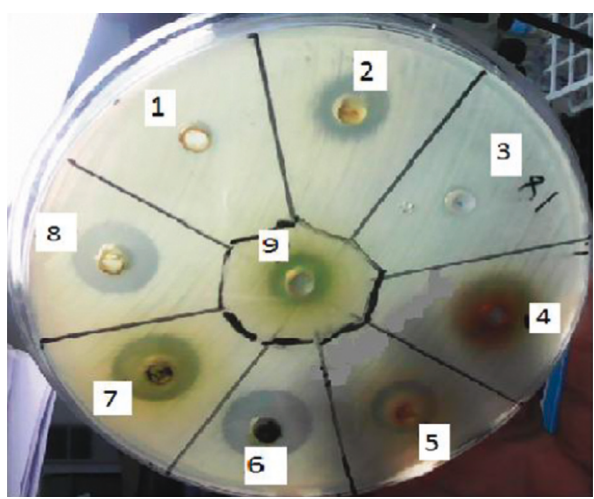

FIgURE 3: Zone of inhibition of constituents of the flowers of $V$. amygdalina against $S$. aureus. Note: 1 and 3 are inhibition zones exhibited by DMSO while 4 represents chloramphenicol; 2, 6, 7, 8, and 9 represent inhibition zone displayed by the hexane extract, chloroform extract, acetone extract, isorhamnetin, and vernolide at $1 \mathrm{mg} / \mathrm{mL} ; 5$ is hexane extract at $0.5 \mathrm{mg} / \mathrm{mL}$.

other hand, the acetone extract displayed broad range of antibacterial activities against all five strains tested in this study. Similar effects have been reported for the leaves extract of $V$. amygdalina against $E$. coli [22]. The wide zone of inhibition of the acetone extract of $V$. amygdalina showed that it had great potential as a remedy for infections/diseases caused by bacterial pathogens. Isorhamnetin isolated in this work from this plant showed modest activity with inhibition zone ranging from 9 to $14 \mathrm{~mm}$ against all bacterial strains. The work presented herein has demonstrated that the acetone extract, vernolide, and isorhamnetin identified in the flowers of $V$. amygdalina had antibacterial activity.

\subsection{Antioxidant Activity}

3.2.1. DPPH Radical Scavenging Assay. DPPH radical scavenging assay is a simple method for finding antioxidants by measuring absorbance at $517 \mathrm{~nm}$ due to the stable 2,2-diphenyl-1-picrylhydrazyl (DPPH) radical [19]. Though their degree varies, the extracts and pure constituents of the flowers of $V$. amygdalina are able to reduce the stable DPPH radical to the yellow-colored diphenylpicrylhydrazicine indicating their potential as radical scavengers. The acetone extract reduced DPPH radicals significantly as compared to the chloroform extract, with 
TABLE 2: Radical scavenging activities of the extracts and constituents of the flowers of $V$. amygdalina.

\begin{tabular}{lcccc}
\hline \multicolumn{2}{c}{ Chloroform extract } & Acetone extract & Isorhamnetin & $\begin{array}{c}\text { Vernolide } \\
\text { \% }\end{array}$ \\
Concentration $(\mu \mathrm{g} / \mathrm{mL})$ & \%PPH inhibition & \% DPH inhibition & \% DPPH inhibition & \% DPPH inhibition \\
\hline 12.5 & $32.8 \pm 0.2$ & $69.0 \pm 1.1$ & $76.5 \pm 0.5$ & $24 \pm 0.4$ \\
25 & $37.1 \pm 0.9$ & $74.5 \pm 0.4$ & $84 \pm 0.6$ & $31 \pm 2.0$ \\
50 & $43.0 \pm 0.4$ & $83.0 \pm 0.2$ & $88 \pm 0.8$ & $37 \pm 0.8$ \\
100 & $54.1 \pm 0.5$ & $91.6 \pm 0.8$ & $94 \pm 0.1$ & $49 \pm 0.2$ \\
\hline
\end{tabular}

The results are reported as mean \pm SD of three replicates. Ascorbic acid was used as the positive control with \% DPPH inhibition of 97.7 .

TABLe 3: Antilipid peroxidation activities of extracts and constituents of the flowers of $V$. amygdalina.

\begin{tabular}{lccc}
\hline Sample name & Absorbance at $500 \mathrm{~nm}$ & \% inhibition & Remark \\
\hline Blank & 0.56 & - & - \\
Ascorbic acid & 0.10 & $83 \pm 0.1$ & - \\
$\mathrm{CHCl}_{3}$ extract & 0.30 & $46 \pm 0.8$ & - \\
Acetone extract & 0.15 & $74 \pm 0.3$ & - \\
Vernolide & 0.35 & $38 \pm 0.7$ & - \\
\hline
\end{tabular}

The results are reported as mean \pm SD of three replicates. Ascorbic acid was used as the positive control.

the earlier inhibiting the radical by $91.46 \%$ at $100 \mu \mathrm{g} / \mathrm{mL}$ (Table 2). This is evident from the low IC50 $(42 \mu \mathrm{g} / \mathrm{mL})$ value observed for the acetone extract. At the same concentration standard, ascorbic acid scavenged the DPPH radical by $97.7 \%$. Plant phenolics are a major group of compounds acting as primary antioxidants or free radical scavengers [23]. Therefore, the observed high free radical scavenging activity of the acetone extract is accounted to the presence of two natural antioxidants, isorhamnetin and luteolin, identified in this study from the flowers of this species. The radical scavenging potential of isorhamnetin was found to be $94 \%$, which is comparable to ascorbic acid used as the positive control. Both isorhamnetin and luteolin are flavonoids with free hydroxyl group which can donate hydrogen and electron and hence responsible for the radical scavenging activities of the flower of $V$. amygdalina. This agrees well with the literature reported for the antioxidant activity of luteolin [23].

3.2.2. Ferric Thiocyanate Method. The degree of lipid peroxidation which was evaluated using ferric thiocyanate method can be used to measure the antioxidant potential of compounds or extracts. Table 3 shows the results of the antilipid peroxide formation of the flower extracts and constituents of $V$. amygdalina.

As depicted in Table 3, the acetone extract and isorhamnetin inhibit peroxide formation by 74 and $80 \%$, respectively, demonstrating their potential in preventing the formation lipid peroxides. The results were turned out to be comparable with ascorbic acid with inhibition of $83 \%$. On the other hand, the chloroform extract and vernolide were shown to have low ability of inhibiting peroxide formation compared with the natural antioxidant. This indicates that the antioxidant compound of the flowers of $V$. amygdalina resides in the acetone extract with the main active ingredient found to be isorhamnetin.

\section{Conclusion}

In conclusion, the work presented herein has demonstrated that the acetone extract and vernolide had strong antibacterial activity compared to chloramphenicol. The antioxidant activities displayed by the acetone extract and isorhamnetin were significant compared with ascorbic acid indicating the potential of the flowers of this species as natural antioxidants. Therefore, biological activities displayed by the flower extracts and constituents of the flowers of $V$. amygdalina corroborate the traditional uses of this plant against various ailments including bacteria.

\section{Conflicts of Interest}

The authors declare that there are no conflicts of interest.

\section{Acknowledgments}

The authors are grateful to Adama Science and Technology University.

\section{Supplementary Materials}

The ${ }^{1} \mathrm{H}-,{ }^{13} \mathrm{C}$, DEPT-135, COSY, HSQC, and HMBC spectra generated for identifying compound $\mathbf{2}$ as vernolide are annexed as a supporting material $1,2,3,4,5$, and 6 , respectively. Likewise, the NMR spectra generated for characterization of isorhamnetin are annexed as supporting material 7-9. 1. 1H-NMR spectrum of vernolide. 2. 13CNMR spectrum of vernolide. 3. DEPT-135 NMR spectrum of vernolide. 4. COSY NMR spectrum of vernolide. 5. HSQC NMR spectrum of vernolide. 6. HMBC NMR spectrum of vernolide. 7. 1H-NMR spectrum of isorhamnetin. 8. 13CNMR spectrum of isorhamnetin. 9. DEPT 135 NMR spectrum of isorhamnetin. (Supplementary Materials)

\section{References}

[1] L. T. Kigigha and E. Onyema, "Antibacterial activity of bitter leaf (Vernonia amygdalina) soup on Staphylococcus aureus and Escherichia coli)," Sky Journal of Microbiology Research, vol. 3, no. 4, pp. 41-45, 2015.

[2] S. K. Yeap, W. Y. Ho, B. K. Beh et al., "Vernonia amygdalina, an ethnoveterinary and ethnomedical used green vegetable with multiple bioactivities," Journal of Medicinal Plants Research, vol. 4, no. 25, pp. 2787-2812, 2010.

[3] A. Mekoya, S. J. Oosting, S. Fernandez-Rivera, and A. J. Van der Zijpp, "Multipurpose fodder trees in the Ethiopian highlands: Farmers' preference and relationship of indigenous 
knowledge of feed value with laboratory indicators," Agricultural Systems, vol. 96, no. 1-3, pp. 184-194, 2008.

[4] A. E. Thompson, D. A. Dierig, and R. Kleiman, "Characterization of Vernonia galamensis germplasm for seed oil content, fatty acid composition, seed weight and chromosome number," Industrial Crops and Products, vol. 2, no. 4, pp. 299-305, 1994.

[5] P. A. Akah and C. L. Okafor, "Blood sugar lowering effect of Vernonia amygdalina Del. in an experimental rabbit model," Phytotherapy Research, vol. 6, no. 3, pp. 171-173, 1992.

[6] I. J. Atangwho, P. E. Ebong, E. U. Eyong, and M. U. Eteng, "Combined administration of extracts of Vernonia amygdalina (Del) and Azadirachta indica (A. Juss) mimic insulin in time-course body weight and glucose regulation in diabetic and non-diabetic rats," Nigerian Journal of Biochemistry and Molecular Biology, vol. 25, pp. 44-49, 2010.

[7] I. I. Ijeh and C. C. Ejike, "Current perspectives on the medicinal potentials of Vernonia amygdalina Del.," Journal of Medicinal Plants Research, vol. 5, pp. 1051-1061, 2011.

[8] J. J. Magadula and P. Erasto, "Bioactive natural products derived from the East African flora," Natural Product Reports, vol. 26, no. 12, pp. 1535-1554, 2009.

[9] A. Adetutu, W. A. Morgan, and O. Corcoran, "Ethnopharmacological survey and in vitro evaluation of woundhealing plants used in South-western Nigeria," Journal of Ethnopharmacology, vol. 137, no. 1, pp. 50-56, 2011.

[10] J. A. K. Noumedem, M. Mihasan, J. R. Kuiate et al., "In vitro antibacterial and antibiotic-potentiation activities of four edible plants against multidrug- resistant gram-negative species," BMC Complementary and Alternative Medicine, vol. 13, p. 190, 2013.

[11] A. C. N. Sobrinho, E. B. de Souza, and R. O. S. Fontenelle, “A review on antimicrobial potential of species of the genus Vernonia (Asteraceae)," Journal of Medicinal Plants Research, vol. 9, no. 31, pp. 838-850, 2015.

[12] G. O. Igile, W. Oleszek, M. Jurzysta, R. Aquino, N. de Tommasi, and C. Pizza, "Vernoniosides D and E, two novel saponins from Vernonia amygdalina," Journal of Natural Products, vol. 58, no. 9, pp. 1438-1443, 1995.

[13] M. Jisaka, H. Ohigashi, T. Takagaki et al., "Bitter steroid glucosides, Vernoniosides A1, A2 and A3 and related B1 from a possible medicinal plant, Vernonia amygdalina, used by wild chimpanzees," Tetrahedron, vol. 48, no. 4, pp. 625-632, 1992.

[14] M. A. Huffman, S. Gotoh, D. Izutsu, K. Koshimizu, and M. S. Kalunde, "Further observations on the use of the medicinal plant Vernonia amygdalina (Del.), by a wild chimpanzee, it's possible effect on parasite load, and its phytochemistry," African Study Monographs, vol. 14, no. 4, pp. 227-240, 1993.

[15] P. Erasto, D. S. Griersoon, and A. J. Afolayan, "Bioactive sesquiterpene lactones from the leaves of Vernonia amygdalina," Journal of Ethnopharmacology, vol. 106, no. 1, pp. 117-120, 2006.

[16] S. F. Sulaiman, N. A. M. Yusoff, I. M. Eldeen, E. M. Seow, A. A. B. Sajak, and K. L. Supriatno, "Correlation between total phenolic and mineral contents with antioxidant activity of eight Malaysian bananas (Musa sp)," Journal of Food Composition and Analysis, vol. 24, no. 1, pp. 1-10, 2011.

[17] M. D. Rivero-Perez, P. Muniz, and M. L. Sanjase, "Antioxidant profile of red wines evaluated by total antioxidant capacity, Scavenger activity, and biomarkers of oxidative stress methodologies," Journal of Agricultural and Food Chemistry, vol. 55, no. 14, pp. 5476-5483, 2007.
[18] A. Nagatsu, "Investigation of anti-oxidative compounds from oil plant seed," Fabad Journal of Pharmaceutical Sciences, vol. 29, pp. 203-210, 2004.

[19] I. Gulcin, Z. Huyut, M. Elmastas, and H. Y. Aboul-Enein, "Radical scavenging and antioxidant activity of tannic acid," Arabian Journal of Chemistry, vol. 3, no. 1, pp. 43-53, 2010.

[20] T. Rabe, D. Mullholland, and J. van Staden, "Isolation and identification of antibacterial compounds from Vernonia colorata leaves," Journal of Ethnopharmacology, vol. 80, no. 1, pp. 91-94, 2002.

[21] I. I. Anibijuwon, B. O. Oladejo, O. Adetitun, and O. M. Kolawole, "Antimicrobial activities of Vernonia amygdalina against oral microbes," Global Journal of Pharmacology, vol. 6, no. 3, pp. 178-185, 2012.

[22] M. N. Alo, C. Anyim, J. C. Igwe, M. Elom, and D. S. Uchenna, "Antibacterial activity of water, ethanol and methanol extracts of Ocimum gratissimum, Vernonia amygdalina and Aframomum melegueta," Advances in Applied Science Research, vol. 3, pp. 844-848, 2012.

[23] P. Erasto, D. S. Grierson, and A. N. Afolaya, "Evaluation of antioxidant activity and the fatty acid profile of the leaves of Vernonia amygdalina growing in South Africa," Food Chemistry, vol. 104, no. 2, pp. 636-642, 2007. 

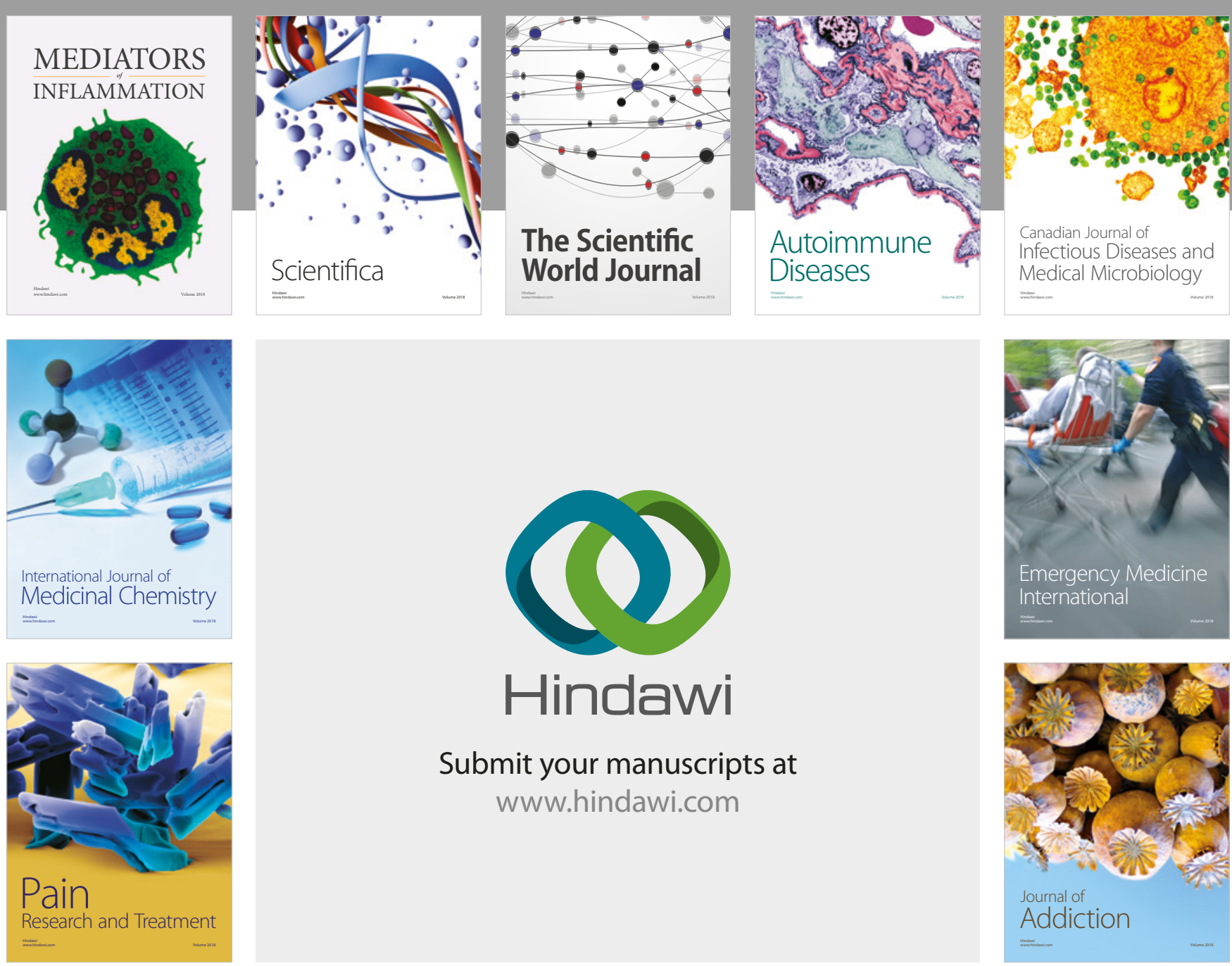

Canadian Journal of
Infectious Diseases and Medical Microbiology

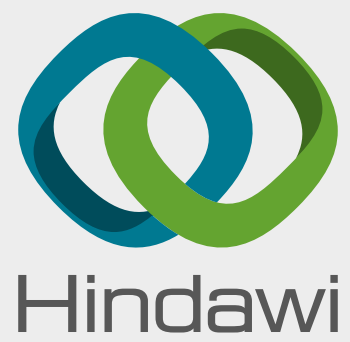

Submit your manuscripts at

www.hindawi.com
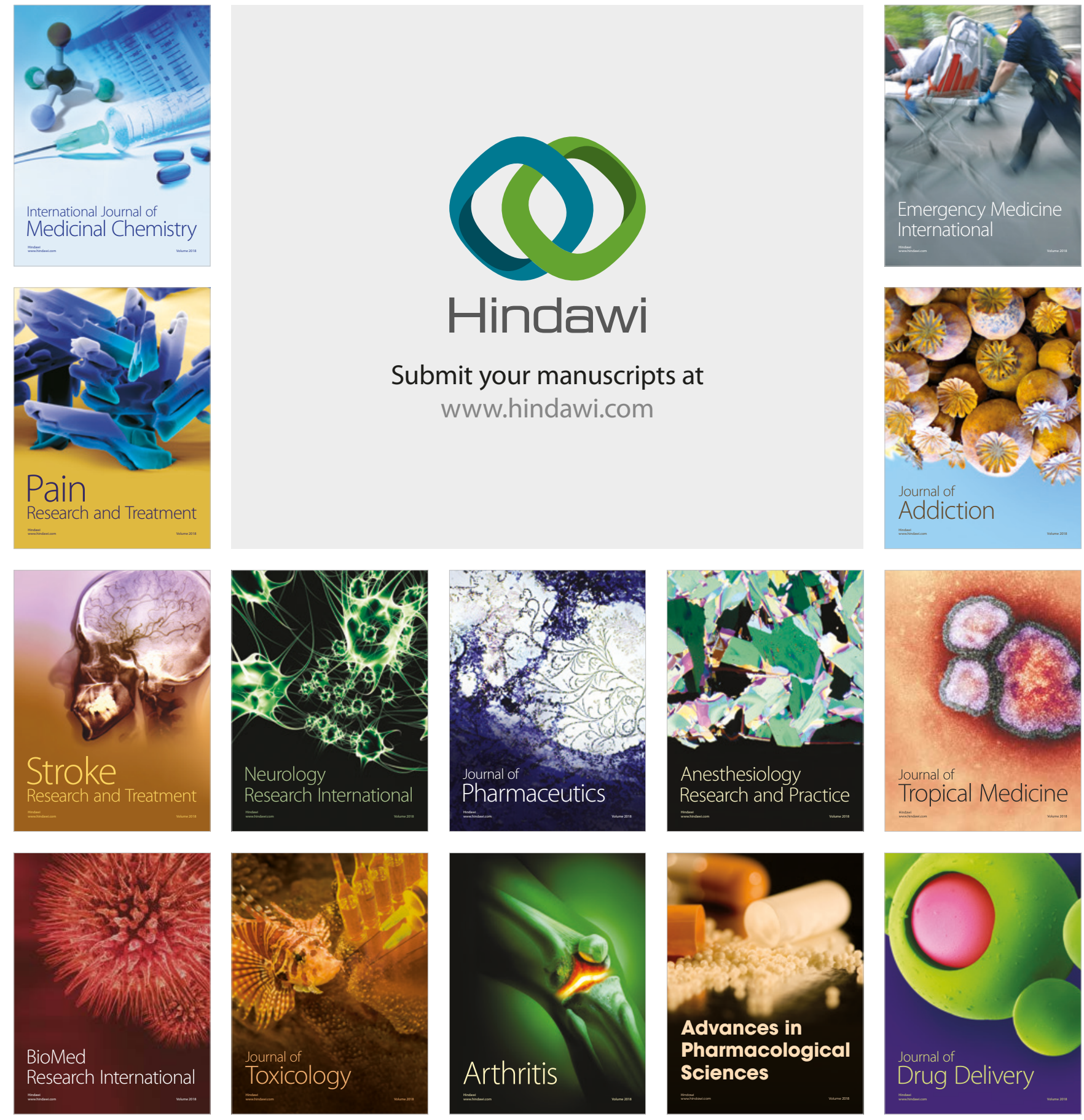